\title{
Requisições de rotina e testes colorimétricos empregados em Química Forense: do preparo das soluções à descrição dos fenômenos químicos.
}

\author{
M. A. F. Costa ${ }^{a, b^{*}}$, N.M. Brito ${ }^{b}$ \\ ${ }^{a}$ Instituto Laboratorial de Análises Forenses, Perícia Oficial de Natureza Criminal do Maranhão, Polícia Civil do Maranhão, São Luís (MA), Brasil \\ ${ }^{b}$ Instituto Federal de Educação, Ciência e Tecnologia do Maranhão, São Luís (MA), Brasil \\ *Endereço de e-mail para correspondência: marcus_de_abreu@hotmail.com.Tel.: +55-98-988640692.
}

Recebido em 30/10/2018; Revisado em 08/09/2019; Aceito em 06/05/2020

\begin{abstract}
Resumo
Em virtude da crescente criminalidade e da necessidade da prova pericial para uma persecução penal eficaz, mais serviços têm sido demandados dos laboratórios de química forense. A imprescindibilidade de realização de todos esses exames, aliados à sua heterogeneidade e ao limitado tempo para emissão de resultados na forma de laudos periciais, requer, além de outras boas práticas de laboratório, que os variados procedimentos metodológicos estejam sistematicamente descritos e organizados, garantindo o rigor científico e a qualidade das análises. Exames para identificação de Cannabis sativa, cocaína, resíduos de disparo de arma de fogo e de artefatos explosivos são amiúde requisitados pelas autoridades competentes e executados em laboratórios de química forense. Este trabalho, além de ser uma revisão das metodologias usadas nos ditos exames, explica os fenômenos químicos envolvidos nos testes colorimétricos de Duquenóis-Levine, Fast Blue B Salt, de Scott, de Griess, do rodizonato de sódio e testes para identificação de nitrato, amônio e compostos aromáticos. Buscou-se proporcionar conhecimento acerca do cerne desses processos para uma interpretação inequívoca e convicta acerca dos resultados obtidos. A atuação profissional do autor, bem como pesquisas em livros, artigos científicos, teses, dissertações e manual de bancada de instituição de perícia criminal de natureza oficial, foram as bases para a consecução deste trabalho.
\end{abstract}

Palavras-Chave: laboratório de química forense; exames de rotina; procedimentos metodológicos; reações químicas.

\begin{abstract}
Due to increasing crime and the need for expert evidence for effective criminal prosecution, services have been required by forensic chemistry laboratories. The indispensability of carrying out all these exams, combined with their heterogeneity and the limited time for issuing results in the form of expert reports, requires, in addition to other good laboratory practices, that the various methodological procedures are systematically described and organized, ensuring the scientific rigor and the quality of analysis. Tests for the identification of Cannabis sativa, cocaine, gunshot residue and explosive devices are often requested by the competent authorities and performed in forensic chemistry laboratories. This work, besides being a review of the methodologies used in the said exams, explains the chemical phenomena involved in the colorimetric tests of Duquenols-Levine, Fast Blue B Salt, modified Scott, Griess, sodium rhodizonate and tests for identification of nitrate, ammonium and aromatic compounds. We sought to provide knowledge about the core of these processes for an unambiguous and convinced interpretation of the results obtained. The author's professional performance, as well as research in books, scientific articles, thesis, dissertations and bench manual of an official criminal expert institution, were the basis for the accomplishment of this work.
\end{abstract}

Keywords: Forensic chemistry laboratory; routine exams; methodology procedures; chemical reactions.

\section{INTRODUÇÃO}

No Brasil é constitucionalmente atribuída às Polícias Civis e Federais a incumbência de apurar infrações penais, ou seja, investigar crimes com a finalidade de elucidá-los [1]. A realização de exames de corpo de delito na própria cena do crime, bem como em vestígios coletados desses locais, é uma diligência valiosa para que 
se possa demonstrar a existência do fato criminoso, buscar a autoria e determinar as condições em que o delito ocorreu, possibilitando a justa condenação e sentenciamento daquele(s) que a lei penal deve alcançar.

A perícia criminal tem seus procedimentos assentados no rigoroso conhecimento científico. Quando conhecimentos de química são empregados para elucidação de crimes, tem-se a especialidade da Criminalística denominada Química Forense, cuja importância se revela no fato de que em laboratórios de investigações criminais de países da Europa e nos Estados Unidos, é a que mais emprega profissionais, seguida da especialidade Biologia Forense [2].

É patente que a criminalidade no Brasil cresceu nos últimos anos, o que tem demandado um número cada vez maior de análises em laboratórios Forenses. Conforme os relatórios de ocorrências do Instituto Laboratorial de Análises Forenses do Maranhão (ILAF/MA), em 2017 foram lavradas 4.642 ocorrências, das quais 3.601 foram direcionadas para exames no laboratório de Química Forense. Já em 2018, das 4.745 ocorrências lavradas, 3.611 foram direcionadas para exames no mesmo laboratório [3 - 4].

Não obstante a possibilidade de realização de análises químicas de interesses forenses por meio de instrumentação analítica moderna, os testes colorimétricos, que se baseiam no desenvolvimento de uma cor para indicar a presença de uma substância (ou de uma classe de substâncias) ainda são bastante comuns, como os testes presuntivos para maconha e cocaína, por exemplo. A análise em materiais para identificação dessas drogas é tão presente na rotina dos laboratórios de Química Forense que, na obra "Procedimento Operacional Padrão Perícia Criminal", da Secretaria Nacional de Segurança Pública [5], na área da Química Forense, abordam-se apenas os exames para identificação de maconha e cocaína.

Exames para detecção de resíduos de disparo de arma de fogo e resíduos de explosão também são rotineiramente requisitados pelas autoridades competentes. O primeiro consta em [5] inserido na área da Balística Forense, e tem por objetivo identificar determinadas espécies químicas nas mãos de suspeitos, vítimas e anteparos diversos. Já em [6], encontram-se quesitos relacionados à presença de material explosivo e/ou seus resíduos em corpos de delito submetidos a exames.

O elevado e crescente número de requisições de exames em laboratórios de Química Forense, bem como o limitado tempo para emissão dos resultados das análises, requer dos órgãos periciais oficiais de natureza criminal que metodologias e formas de preparação de reagentes estejam organizadamente descritas e acessíveis aos analistas. Ainda, para a correta interpretação dos dados obtidos e formação de convicção por parte do perito, é deveras importante o conhecimento dos mecanismos envolvidos nos exames químicos executados.

Este trabalho trata do preparo de soluções necessárias à realização de testes colorimétricos para identificação de maconha e cocaína, detecção de resíduos de disparo de arma de fogo e resíduos de explosão, bem como interpreta os resultados obtidos em termos das reações químicas envolvidas, uma vez que esses exames são frequentemente requisitados pelas autoridades competentes e podem ser considerados como sendo da rotina de um laboratório de Química Forense.

\section{TESTES PARA IDENTIFICAÇÃO DE MACONHA (Cannabis sativa)}

A Cannabis sativa, conhecida popularmente como maconha, é a droga ilícita mais cultivada, traficada e consumida do mundo. Os canabinoides, que só são encontrados nesse vegetal, responsáveis pela atividade farmacológica da planta, são pertencentes à classe terpenofenólica e são classificados em psicoativos $\left(\Delta^{9}\right.$ THC, por exemplo) e não psicoativos (canabidiol e canabinol, por exemplo). O $\Delta^{9}$-THC é a principal substância responsável pelo efeito psicótico da Cannabis sativa [7].

Para a Cannabis sativa, os testes de Duquenóis-Levine e do Fast Blue B Salt são exames colorimétricos bastante utilizados para detecção de canabinoides [7].

\subsection{Teste de Duquenois-Levine}

Neste teste utiliza-se um reagente que leva o mesmo nome e cujo preparo se dá pela pesagem de $2,0 \mathrm{~g}$ de vanilina seguida da dissolução dessa quantidade em 100 $\mathrm{mL}$ de álcool etílico 95\%. Após, acrescenta-se 2,5 mL de acetaldeído [8].

Para realização do exame, coloca-se uma pequena quantidade da amostra a ser analisada (cerca 0,020g) em um tubo de ensaio e adiciona-se $2 \mathrm{~mL}$ da solução de Duquenóis-Levine. Agita-se a mistura por 1 minuto. Adiciona-se $2 \mathrm{~mL}$ de ácido clorídrico concentrado e agitase por alguns segundos. Deixa-se a mistura em repouso por alguns minutos. Se houver desenvolvimento de uma coloração dentro de até 3 minutos, adiciona-se $2 \mathrm{~mL}$ de clorofórmio. A coloração violeta na camada inferior (clorofórmica) indica a possível presença de canabinoides na amostra [8]. A Figura 1 representa a formação do cromóforo, pelo que é possível presumir que a amostra em questão se trata de Cannabis sativa (maconha). 


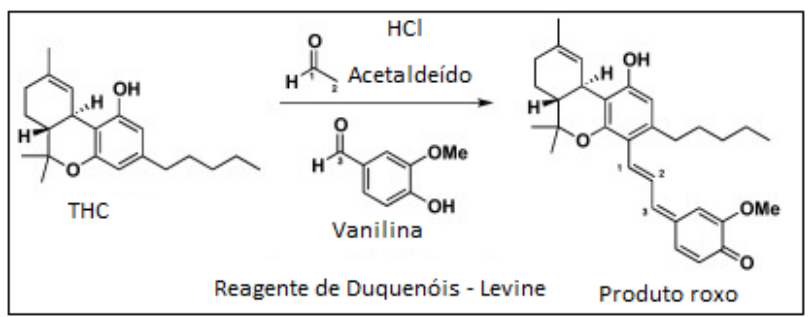

Figura 1. Reação que se processa durante o teste de Duquenóis-Levine, com resultado positivo para maconha [9].

\subsection{Teste com Fast Blue B Salt}

Para realização do teste colorimétrico com o Fast Blue $B$ Salt (cloreto de di-o-anisidina tetrazolio), presuntivo da presença de canabinoides, recomenda-se o seguinte procedimento: após 2 dobras em 2 papéis de filtro circular para adquirir a forma de 2 funis, sobrepô-los e colocar uma pequena quantidade da amostra questionada no centro do funil superior, seguido da adição de 2 gotas de éter de petróleo, de forma que o extrato penetre o funil de papel de filtro inferior. Após, descarta-se o funil superior e aguarda-se a secagem do inferior. Em seguida, pequeníssima porção da mistura composta por Fast Blue $B$ Salt e sulfato de sódio anidro (1\% em massa de Fast Blue $B$ Salt) é adicionada ao centro deste, seguida da adição de 2 gotas de solução aquosa de bicarbonato de sódio a $10 \%(\mathrm{~m} / \mathrm{m})$. Uma mancha vermelha é indicativa da presença de canabinoides [8].

Também se encontra na literatura a realização de teste preliminar para identificação de Cannabis sativa onde 5 gotas de extrato de éter de petróleo do vegetal são aplicadas a um papel de filtro e, após evaporação do solvente, são adicionadas 5 gotas de solução de Fast Blue $B$ Salt $0,25 \%(\mathrm{~m} / \mathrm{v})$, preparada por meio da dissolução de 0,025g dessa substância em $10 \mathrm{~mL}$ de água destilada [7].

Quando este sal é utilizado na forma de solução líquida, para revelação de canabinoides após separação por cromatografia em camada delgada (CCD), encontrase na literatura mais de uma forma de sua preparação. Referência [8] recomenda sua preparação de duas formas: 1. Dissolução de $50 \mathrm{mg}$ deste sal em $20 \mathrm{~mL}$ de solução de hidróxido de sódio a $0,1 \mathrm{~N} ; 2$. Dissolução de $50 \mathrm{mg}$ deste sal em $1 \mathrm{~mL}$ de água, seguido da adição de $20 \mathrm{~mL}$ de metanol. A estrutura do possível cromóforo responsável por tal coloração está representada na Figura 2.



Figura 2. Possível produto formado na reação com Fast Blue B Salt [7].

\section{IDENTIFICAÇÃO DE COCAÍNA}

O alcaloide cocaína, extraído das folhas do vegetal Erytroxylum coca, é a segunda droga ilícita mais consumida em todo o mundo. Apresenta-se na forma do sal cloridrato de cocaína, ocasião em que a droga é aspirada ou injetada, ou na forma de cocaína base livre, chamada popularmente de crack, merla, pasta base etc., ocasião em que a droga é fumada [7]. Assim como para a maconha, além dos exames definitivos, também são realizados testes colorimétricos presuntivos para a cocaína, sendo o teste de Scott (teste do tiocianato de cobalto modificado) bastante empregado em laboratórios de química forense.

A UNODC (United Nations Office on Drugs and Crime) recomenda a preparação desse reagente dissolvendo $1 \mathrm{~g}$ de tiocianato de cobalto em $50 \mathrm{~mL}$ de uma solução a $10 \%(\mathrm{v} / \mathrm{v})$ de ácido acético, seguida da adição de $50 \mathrm{~mL}$ de glicerina [10].

Para a realização do teste de Scott, [10] recomenda seguir as 3 etapas abaixo descritas:

$1^{a}$ etapa: colocar uma pequena quantidade da amostra questionada (não mais que $1 \mathrm{mg}$ ) em um tubo de ensaio seguida da adição de 5 gotas do reagente de Scott e agitar por 10 segundos. Deve ser formado um precipitado e uma solução, ambos de cor azul;

$2^{\mathrm{a}}$ etapa: adicionar 1 gota de ácido clorídrico concentrado. Agitar a mistura por alguns segundos. A solução azul deve se tornar rosa. Caso essa mudança de cor não ocorra, recomenda-se acrescentar mais uma gota do ácido clorídrico concentrado. Se ainda assim a mudança de cor não ocorrer, recomenda-se repetir o teste com uma porção menor do material;

$3^{a}$ etapa: Adicionam-se 5 gotas de clorofórmio e o sistema é novamente agitado. Deve-se obter uma fase inferior (clorofórmica) de cor azul e uma fase superior de cor rosa nessa etapa.

O resultado será positivo para cocaína se ocorrer, necessariamente, os fenômenos descritos em cada uma das três etapas [10].

$\mathrm{Na}$ solução reagente, o íon cobalto (II) está formando um complexo octaédrico com moléculas de água e íons tiocianato. Atribui-se a cor rosa do reagente às moléculas de água que ocupam sítios de coordenação desse íon. Logo, não existindo cocaína na amostra questionada, a água permanecerá em sítios de coordenação ao redor do íon cobalto (II) (equilíbrio deslocado para a esquerda), mantendo a cor rosa do complexo, segundo o seguinte equilíbrio sugerido por [11].

$\left[\mathrm{Co}(\mathrm{SCN})\left(\mathrm{H}_{2} \mathrm{O}\right)_{5}\right]_{(\mathrm{aq})}^{+}+3 \mathrm{SCN}_{(\mathrm{aq})}^{-} \rightleftharpoons\left[\mathrm{Co}(\mathrm{SCN})_{4}\right]_{(\mathrm{aq})}^{2-}+5 \mathrm{H}_{2} \mathrm{O}_{(\mathrm{l})}$

Quando cocaína está presente, cada duas moléculas de água são substituídas por uma molécula do alcaloide (o 
ligante cocaína é bidentado), o que irá conferir cor azul ao novo complexo formado, mais solúvel em solvente orgânico, como o clorofórmio. Referência [12] sugeriu a estrutura representada na Figura 3 para esse complexo.

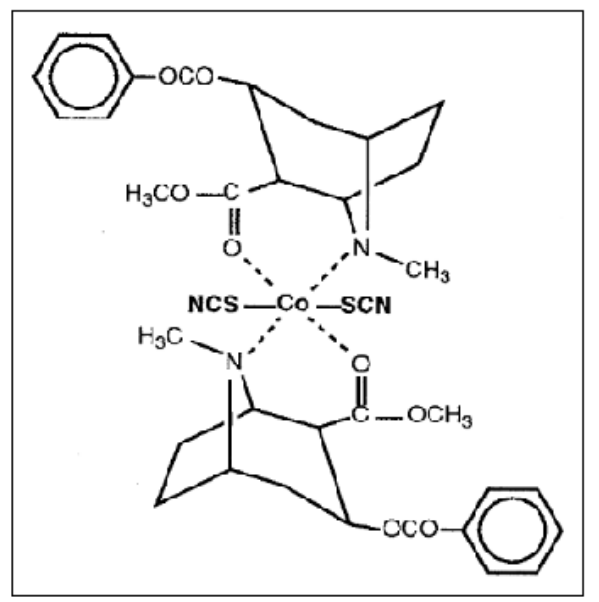

Figura 3. Complexo cocaína-tiocianato de cobalto [12].

\subsection{Resíduos de disparo de arma de fogo}

$\mathrm{Na}$ análise dos resíduos de disparo de arma de fogo o corpo de delito apresentado varia, podendo ser a própria arma, as mãos de um suspeito de ter efetuado disparos, objetos diversos, vestes, veículos etc. Embora este trabalho verse sobre a discussão dos fenômenos observados em alguns testes colorimétricos no âmbito da Química Forense, ressalte-se que diferentes técnicas analíticas instrumentais, como Espectrofotometria de Absorção Atômica, Espectrometria de Emissão com Fonte de Plasma e Espectrometria de Massas com Fonte de Plasma Induzido, podem (e são) utilizadas na análise de resíduos de disparo de arma de fogo, sendo a sensibilidade o principal atributo dessas técnicas quando comparadas aos testes colorimétricos [13]. Referência [14] destaca que Microscopia Eletrônica de Varredura com Espectrômetro de Dispersão de Energia de Raios X (MEV-EDX) é a técnica mais utilizada para essa finalidade, visto que combina informações sobre morfologia e imagem, revelando se os elementos químicos de interesse encontram-se na mesma partícula, o que confere grande especificidade a essa técnica.

Os ensaios colorimétricos para identificação desses resíduos compreendem os testes de Griess e do rodizonato de sódio. $\mathrm{O}$ primeiro busca detectar o nitrito $\left(\mathrm{NO}_{2}{ }^{-}\right)$ formado pela decomposição das substâncias nitrocelulose (ingrediente ativo existente nas pólvoras de base simples) e nitroglicerina (ingrediente ativo existente, juntamente com a nitrocelulose, nas pólvoras de base dupla) [15]. Ressalte-se, porém, que os íons nitrito sobre a ação do oxigênio do ar, da umidade e da temperatura podem se converter em nitratos ou volatilizarem na forma de ácido nitroso. Assim, um resultado negativo não indica que o disparo não tenha sido efetuado [13]. Ainda, um resultado positivo para essa espécie química não pode ser atribuído exclusivamente ao disparo de arma de fogo, visto que pode ser originário de outras matrizes, como urina, cinza de cigarro, produtos alimentícios, fertilizantes, dentre outros [15].

No teste do rodizonato de sódio o que se pretende é detectar chumbo, oriundo das substâncias trinitroresorcinato de chumbo ou estifinato de chumbo, componentes da mistura iniciadora na espoleta, além do chumbo oriundo do desgaste ocasionado pelo atrito entre o projétil constituído por esse metal e o cano da arma [1415]. Também é possível a identificação de íons bário proveniente da substância nitrato de bário, existente na mistura iniciadora da espoleta, embora com uma sensibilidade inferior quando comparada à do íon chumbo [16].

Cabe ressaltar que o teste do rodizonato de sódio também possui limitações. A não detecção dos elementos em questão não significa que não houve disparo de arma de fogo, pois o método possui baixa sensibilidade. Adicionalmente, a detecção desses elementos não necessariamente comprova que estes são oriundos do disparo, já que é possível que o suporte esteja contaminado devido a fatores ambientais e ocupacionais. O chumbo, por exemplo, pode estar presente em soldas, placas de bateria, algumas tintas e em emissões oriundas da combustão de derivados de petróleo com aditivos. Já o bário pode estar presente na composição de papéis, tintas e graxa automotiva, entre outros materiais [17].

\section{TESTE DE GRIESS PARA DETECÇÃO DE NITRITO $\left(\mathrm{NO}_{2}^{-}\right)$}

Este teste envolve a reação de diazotação (formação do íon diazônio a partir da reação do ácido sulfanílico com o nitrito) e a reação de copulação (formação do azocomposto, de cor rosa, a partir da reação entre o íon diazônio e a $\alpha$-naftilamina). A diazotação é favorecida por baixos valores de $\mathrm{pH}$ (em torno de 1,4), temperatura em torno de $20^{\circ} \mathrm{C}$. Para a etapa de copulação deve-se aguardar cerca de 3 minutos para que a diazotação se complete. Cerca de 15 minutos após o início da segunda etapa é possível observar a cor rosa, característica do azocomposto formado [18]. A Figura 4 representa as reações de diazotação (a) copulação (b). 
a)

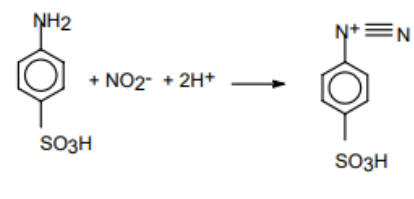

ácido sulfanílico

ion diazônio

b)

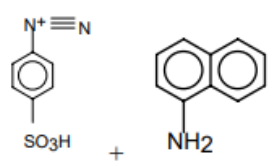

ion diazônio $\alpha$-naftilamina

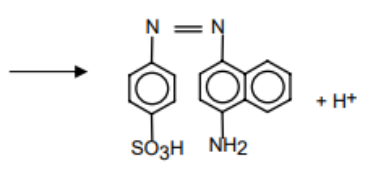

azocomposto

Figura 4. Reações de diazotação (a) e copulação (b) (Adaptado de [18]).

A Referência [19] descreve a preparação da solução de ácido sulfanílico de modo a se obter uma concentração de $0,5 \%(\mathrm{~m} / \mathrm{v})$ em ácido acético $25 \%$ (um leve aquecimento pode ser necessário para dissolução dos cristais). Com relação à solução de $\alpha$-naftilamina, após os procedimentos descritos nessa mesma referência, a concentração será de $0,1 \%(\mathrm{~m} / \mathrm{v})$ em metanol.

Referência [20] descreve o seguinte procedimento, para determinação qualitativa do íon nitrito: colocar $1 \mathrm{~mL}$ de solução aquosa da amostra questionada em um tubo de ensaio e acrescentar 1 gota de ácido clorídrico concentrado. Após agitar a mistura, adicionar 4 gotas da solução de ácido sulfanílico (concentração $0,5 \%$ (m/v) em ácido acético $25 \%$ ) e 4 gotas da solução de $\alpha$-naftilamina (concentração $0,1 \%(\mathrm{~m} / \mathrm{v})$ em metanol). Havendo nitrito na amostra, o azocomposto será produzido e poderá ser observada sua coloração rosa característica. Quando o nitrito está em elevadas concentrações, a coloração se torna amarela [21].

\section{TESTE DO RODIZONATO DE SÓDIO PARA DETECÇÃO CHUMBO E BÁRIO}

Esse teste se baseia na reação de Feigl-Suter, onde o rodizonato de sódio reage, em meio ácido, com cátions de chumbo e/ou bário (representados por $\mathrm{M}^{2+}$ na reação mostrada na Figura 5) para formar complexos de cor rosa $\left(\right.$ com o $\mathrm{Pb}^{+2}$ ) ou laranja (com o $\mathrm{Ba}^{2+}$ ) [22].



Figura 5. Reação de Feigl-Suter [14]

Com relação à coleta dos vestígios para realização do exame, pode-se proceder de duas maneiras. A primeira

diz respeito à situação em que o profissional já dispõe da estrutura necessária para aplicação dos reagentes e visualização dos resultados, ou seja, no laboratório de química forense. Para tal, pode-se proceder como descrito em [16], onde um papel de filtro é umedecido com solução preparada pela dissolução de $85 \mathrm{~g}$ de ácido tartárico e 2,5g de ácido benzóico em $1000 \mathrm{~mL}$ de água ultrapura e, em seguida, pressioado contra o corpo de delito (mãos do atirador, por exemplo) por 1 minuto. Após, o papel de filtro é completamente seco com o auxílio de um secador de cabelo, seguido da aspersão de solução de rodizonato de sódio $0,02 \%(\mathrm{~m} / \mathrm{v})$ sobre sua superfície. O papel de filtro é novamente seco.

Em uma outra ocasião, pode haver necessidade de guarda do vestígio coletado para transporte até o laboratório. Para tal, uma película adesiva transparente, tipo contact, é firmemente pressionada sobre a superfície questionada. Remove-se a película e afixa-se sobre a mesma face da folha de onde foi retirada. Já no laboratório, remove-se a película de seu suporte e borrifase solução de ácido tartárico a $10 \%$ sobre sua face aderente. Após 5 minutos, solução aquosa de rodizonato de sódio $0,02 \%(\mathrm{~m} / \mathrm{v})$ também é borrifada sobre a mesma face. Em seguida, uma folha de papel fotográfico é pressionada por 5 minutos a uma pressão de 2,1 atm sobre a face adesiva da película. [16].

Nos dois casos, ao final do procedimento, pontos de cor rosa indicarão a presença de chumbo, enquanto que pontos de cor laranja indicarão a presença de bário, ambas espécies químicas existentes em resíduos de disparo de arma de fogo.

\section{RESÍDUOS DE EXPLOSÃO}

Misturas contendo sais oxidantes fortes, excetuandose os explosivos utilizados com fins militares, são os artefatos mais utilizados de forma legítima (como pirotécnicos ou em demolições) e também em ações criminosas [23] (explosão de caixa eletrônico, por exemplo). É importante que a perícia, ainda que não disponha de meios técnico científicos para identificar taxativamente o explosivo utilizado, indique, pelos métodos disponíveis, qual tipo de explosivo pode ter sido utilizado durante a ação delituosa, o que auxiliará a investigação a identificar sua origem e envolvidos no crime.

Sais de nitrato e clorato são bastante utilizados como agentes oxidantes em misturas explosivas. Estes, que serão sempre os componentes majoritários e que podem ser combinados em diferentes proporções, são misturados com materiais combustíveis, como carvão, óleo combustível, ou açúcar. A pólvora negra, por exemplo, é um explosivo cuja composição é $75 \%$ nitrato de potássio. Já a cloratita possui $80 \%$ de clorato de sódio em sua composição. Por sua vez, o ANFO (Ammonium 
Nitrate/Fuel Oil) possui nitrato de amônio em 90\% de sua composição. O que se busca nos exames em resíduos de pós-explosão é principalmente as espécies químicas em excesso e que não reagiram, quais sejam, os sais oxidantes [23]. Devido ao fato de que combustíveis derivados do petróleo tem sido bastante utilizados em misturas explosivas, também é pertinente a realização de exames para detecção de compostos aromáticos, abundantes nessas matrizes.

\subsection{Teste para detecção de nitrato $\left(\mathrm{NO}_{3}{ }^{-}\right)$}

Um tipo de reação de nitração de composto aromático pode ser utilizada como método colorimétrico para identificar a presença do ânion nitrato em resíduos de pósexplosão. Para tal, utiliza-se reagente de Caron, que é preparado pela dissolução de $5 \mathrm{mg}$ de difenilamina em $100 \mathrm{~mL}$ de ácido sulfúrico concentrado, seguido da adição cuidadosa de $40 \mathrm{~mL}$ de água e 2 a $3 \mathrm{~mL}$ de ácido clorídrico a $0,1 \quad \mathrm{~N}$ [24]. O ensaio é realizado acrescentando-se $1 \mathrm{~mL}$ de solução aquosa da amostra questionada a um tubo de ensaio e em seguida adicionamse gotas do reagente de Caron (até o limite de $1 \mathrm{~mL}$ desse reagente). Os isômeros de posição formados no produto da reação mostrada na figura 6 são os responsáveis pela cor azul intensa de um resultado positivo para a presença de nitrato na amostra questionada [25].

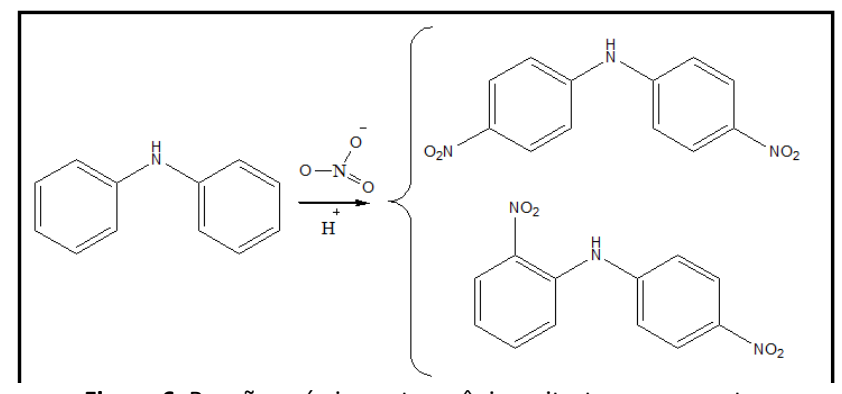

Figura 6. Reação química entre o ânion nitrato e o reagente difenilamina (adaptado de [25]).

Importante salientar que esse mesmo reagente também é empregado na identificação de nitrito [24], ocasião em que o produto formado terá coloração violeta, conforme reação química mostrada na figura 7 .

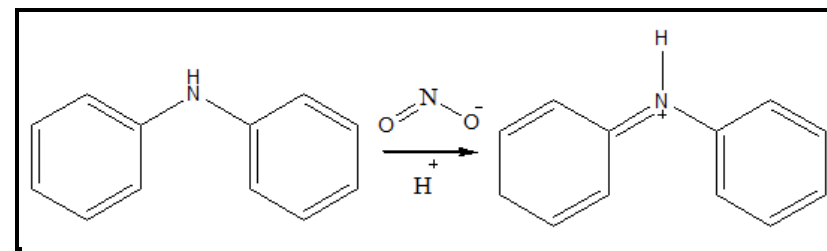

Figura 7. Formação do produto de cor azul intensa (adaptado de [25]).

Seguindo o procedimento abordado, os autores têm obtido resultados satisfatórios para determinação qualitativa do ânion nitrato em ocorrências envolvendo resíduos de pós-explosão.

\subsection{Teste para detecção de amônio $\left(\mathrm{NH}_{4}^{+}\right)$}

O cátion amônio, presente no nitrato de amônio, um sal oxidante passível de utilização em misturas explosivas, pode ser detectado pelo uso do reagente de Nessler ${ }^{1}$.

Um dos métodos utilizados pelo ILAF/MA para determinação qualitativa do cátion amônio consiste em transferir uma alíquota de $0,5 \mathrm{~mL}$ de solução aquosa da amostra questionada para um tubo de ensaio e em seguida acrescentar $1 \mathrm{~mL}$ do reagente de Nessler [26]. A formação de um precipitado de cor castanho-alaranjado indica a presença do íon amônio. A reação da amônia livre (formada a partir da reação do íon amônio com água) com o reagente de Nessler (uma solução alcalina de tetraiodomercurato (II) de potássio) pode é representada na Eq. 2 [27].

$$
2 \mathrm{~K}_{2}\left[\mathrm{HgI}_{4}\right]+2 \mathrm{NH}_{3} \gtrless \mathrm{NH}_{2} \mathrm{Hg}_{2} \mathrm{I}_{3}+4 \mathrm{KI}+\mathrm{NH}_{4} \mathrm{I}
$$

\subsection{Determinação qualitativa de compostos aromáticos}

Considerando que combustíveis como gasolina e óleo diesel possuem substâncias aromáticas em suas composições [28], referência [29] propõe o emprego do reagente de Marquis $^{2}$ para indicar reação com gasolina, dentre outras substâncias, como querosene, varsol (mistura de hidrocarbonetos), benzeno, xileno, tolueno etc. $\mathrm{O}$ procedimento consiste em misturar $5 \mathrm{~mL}$ do material em análise com $30 \mathrm{~mL}$ de $\mathrm{HCl} 0,1 \mathrm{~N}$. Em seguida, adiciona-se $5 \mathrm{~mL}$ de tetracloreto de carbono $\left(\mathrm{CCl}_{4}\right)$. A mistura é agitada energicamente. Após separação das fases por centrifugação, despreza-se a camada superior e acrescenta-se ao conteúdo do tubo 5 $\mathrm{mL}$ do reagente de Marquis. Por fim, após agitar, centrifuga-se a mistura por 5 minutos a $2000 \mathrm{rpm}$. O surgimento de uma cor rosa-avermelhada é atribuído ao carbênio formado no final do mecanismo da reação química mostrada na figura 8 [30], indicando a presença de substância(s) aromática(s), que faz(em) parte da composição de combustíveis derivados do petróleo, como gasolina e óleo diesel.

\footnotetext{
${ }^{1}$ Preparo do reagente de Nessler: Dissolver $7 \mathrm{~g}$ de iodeto de potássio em $30 \mathrm{~mL}$ de água. Em seguida, adicionar solução de cloreto de mercúrio (preparada pela dissolução de $3,4 \mathrm{~g}$ de $\mathrm{HgCl}_{2}$ em $60 \mathrm{~mL}$ de água) sob agitação e até a formação de pequena quantidade de precipitado vermelho permanente. Em seguida, adiciona-se vagarosamente uma solução de hidróxido de sódio preparada pela dissolução de $24 \mathrm{~g}$ de $\mathrm{NaOH}$ em $60 \mathrm{~mL}$ de água. Após, dilui-se a mistura com água até o volume de $200 \mathrm{~mL}$. Adiciona-se, pouco a pouco, a solução restante de $\mathrm{HgCl}_{2}$ até formação de pequena quantidade de precipitado permanente. Deixa-se decantar até a solução ficar transparente e elimina-se a parte insolúvel por filtração com algodão de vidro [24].

${ }^{2}$ Reagente de Marquis: $4 \mathrm{~mL}$ de solução de formaldeído a 40\% em 100 $\mathrm{mL}$ de ácido sulfúrico concentrado [24].
} 


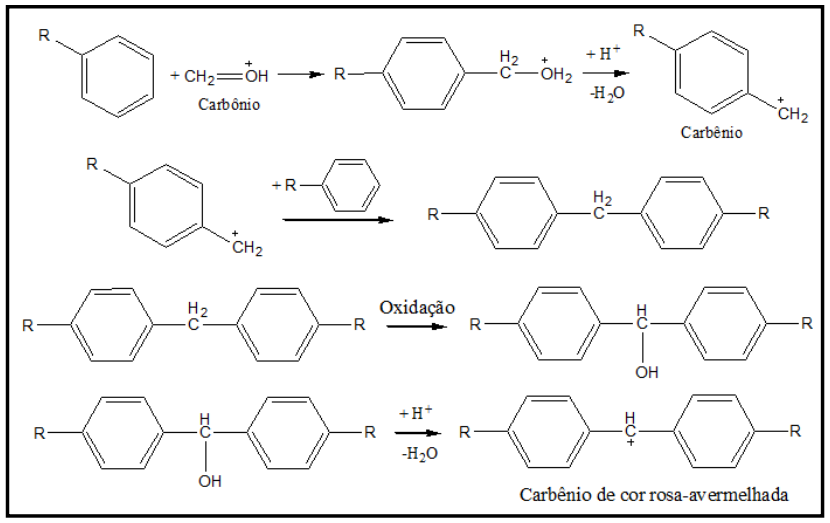

Figura 6. Reação entre uma substância aromática e o reativo de Marquis. (Adaptado de [30]).

$\mathrm{O}$ reagente de Marquis também é utilizado em Química Forense para identificação de compostos anfetamínicos, visto que estes também possuem anel aromático em suas estruturas. Sob ação desse reagente, anfetamina forma um produto laranja, enquanto que metanfetamina forma um produto de coloração verdeamarelada [30].

\section{CONCLUSÕES}

Embora se tenha avançado bastante em termos de instrumentação analítica moderna, os métodos colorimétricos ainda estão muito presentes na rotina de laboratórios de investigação criminal em diferentes regiões do país, pois são de simples execução e, geralmente, apresentam menor custo. Não obstante, devese considerar que os métodos colorimétricos apresentam maiores limitações em importantes parâmetros analíticos, como sensibilidade e seletividade, considerados baixos quando comparados com as técnicas analíticas instrumentais.

Ainda que a realização de um teste colorimétrico seja considerada uma tarefa de simples execução, os métodos a serem adotados devem estar bem definidos. Ademais, recomenda-se que, sempre que um novo método venha a ser incorporado à rotina do laboratório, seja procedida à sua verificação.

Finalmente, para que o perito químico forense tenha maior convicção e segurança na liberação de seus laudos, é fundamental interpretar, em termos do rearranjo dos átomos, os resultados obtidos em nível macroscópico, ou seja, as mudanças de cores ocorridas no sistema.

\section{AGRADECIMENTOS}

Os autores agradecem ao Instituto Laboratorial de Análises Forenses, órgão vinculado à Perícia Oficial de Natureza Criminal do Maranhão, pela disponibilização de dados e pelo incentivo à constante pesquisa no campo das ciências forenses, bem como ao Instituto Federal de
Educação, Ciência e Tecnologia do Maranhão, pelas orientações necessárias à pesquisa científica.

\section{REFERÊNCIAS BIBLIOGRÁFICAS}

[1] Brasil. Constituição da República Federativa do Brasil (1988), Coordenação de Edições Técnicas, Brasil (2016) 90-91.

[2] R. P. O. Branco. Química forense sob olhares eletrônicos, Millenium, Brasil (2013) 61.

[3] Maranhão. ILAF. Relatório de ocorrências do Instituto Laboratorial de Análises Forenses - 2016. Instituto Laboratorial de Análises Forenses do Maranhão, gestão 2015/2018 (2017).

[4] Maranhão. ILAF. Relatório de ocorrências do Instituto Laboratorial de Análises Forenses - 2017. Instituto Laboratorial de Análises Forenses do Maranhão, gestão 2015/2018 (2018).

[5] Brasil. Secretaria Nacional de Segurança Pública. Procedimento Operacional Padrão Perícia Criminal, Ministério da Justiça, Brasil (2013) 223-237.

[6] Brasil. Departamento de Polícia Federal. Manual de orientação de quesitos da perícia criminal, Diretoria Técnico-Científica (2012) 51-52.

[7] J.L. Costa; D.C. Bordin; M. Messias; R. Lanaro; S.O.S. Cazenave. Análise forense: pesquisa de drogas vegetais interferentes de testes colorimétricos para identificação dos canabinoides da maconha (Cannabis sativa L.). Quim. Nova 35: 2040-2043 (2012).

[8] United Nations Office on Drugs and Crime. Recommended methods for the identification and analysis of cannabis and cannabis products, Laboratory and Scientific Section (2009) 33-43.

[9] R.C.A. Isaacs. A structure-reactivity relationship driven approach to the identification of a color test protocol for the presumptive indication of synthetic cannabimimetic drugs of abuse. Forensic Sci. Int. 242: 135-141 (2014).

[10] United Nations Office on Drugs and Crime. Recommended methods for the identification and analysis of cocaine in seized materials, Laboratory and Scientific Section (2012) 20-21.

[11] J.W. McGill; C.A. Dixon; D. Ritter; J.D. Sides. Discovery of an interesting temperature effect on the sensitivity of the cobalt thiocyanate test for cocaine. Microgram J. 6. 26-35 (2008).

[12] K. Oguri; W. Sachiko; S. Eto; H. Yamada. Specificity and mechanism of the color reaction of cocaine with cobaltous thiocyanate. Jpn. J. Toxicol. Environ. Health. 41. 274-279 (1995).

[13] E.L.T. dos Reis; J.E.S. Sarkis; C. Rodrigues. Identificação de resíduos de disparos de armas de fogo por meio da técnica de espectrometria de massas de alta resolução com fonte de plasma indutivo. Quim. Nova 27: 409-413 (2004).

[14] A. Duarte. Caracterização elementar de resíduos de disparo de armas de fogo gerados por munição de fabricação brasileira. Tese de Doutorado, Programa de 
Pós-Graduação em Ciência dos Materiais, Universidade Federal do Rio Grande do Sul (2014).

[15] M.F. de Oliveira; I.C. Eleotério; J.A. Velho. Fundamentos de química forense: uma análise prática da química que soluciona crimes, Millenium, Brasil (2012) 227-245.

[16] D. Werner; A-L. Gassner; J. Marti; S. Christen; P. Wyss; C. Weyermann. Comparison of three collection methods for the sodium rhodizonate detection of gunshot residues on hands. Sci. Justice 60: 63-71 (2020).

[17] A. Martiny; A.L. Pinto. Aplicação da microscopia eletrônica de varredura à análise de resíduos de tiro. RMCT XXV: 24-35 (2008).

[18] N.A. Dias. Estudo sistemático da redução de nitrato por hidrazina para determinação de nitratos em águas e aditivos alimentícios, em fluxo. Dissertação de Mestrado, Programa de Pós-Graduação em Ciências da Coordenadoria de Controle de Doenças da Secretaria de Estado da Saúde de São Paulo, São Paulo (2005).

[19] N. Petraco; M. Yander; J. Sardone. A method for the quantitative determination of nitrites in gunshot residue cases. Forensic Sci. Int. 18: 85-92 (1981).

[20] Maranhão. Superintendência de Polícia TécnicoCientífica. Pesquisa de nitrito. São Luís: (s.n., 20--).

[21] Merck. Microbiology Manual 12th Edition. Merck, (20??) 303. Retirado em 30/04/2020, de http://www.laboquimia.es/pdf_catalogo/MERCK_Manual de_microbiologia_12a_edicion.pdf.

[22] L.C. Mota. Detecção de resíduos de disparo de arma de fogo em larvas cadavéricas por ICP OES. Dissertação de Mestrado, Programa de Pós-Graduação em Química, Universidade Federal do Espírito Santo (2018).

[23] F.Zapata; C. García-Ruiz. Analysis of different materials subjected to open-air explosions in search of explosive traces by Raman microscopy. Forensic Sci. Int. 275: 57-64 (2017).

[24] T. Morita; R.M.V. Assumpção. Manual de soluções, reagentes e solventes: padronização, preparação, purificação, indicadores de segurança, descarte de produtos químicos, Blucher, Brasil (2007) 319-362.

[25] R. Bartzatt; L. Donigan. The colorimetric determination of nitrate anion in aqueous and solid samples utilizing an aromatic derivative in acidic solvent. Toxicol. and Environ. Chem. 86: 75-85 (2004).

[26] Maranhão. Instituto Laboratorial de Análises Forenses - ILAF/MA. Serviço de Química Forense QFO. Manual de Bancada. São Luís: (s.n., 2018).

[27] J.S. Santos. Desenvolvimento e otimização de metodologias para a determinação de nitrogênio. Dissertação de Mestrado, Programa de Pós-Graduação em Agroquímica, Universidade Federal de Viçosa (2007). [28] C.G.D. Peixoto; Y.L.S. Costa; A.S. de Araujo; V.J. Fernandes Junior. Caracterização físico-química de óleo diesel rodoviário e marítimo por técnicas convencionais e destilação simulada por cromatografia gasosa. Anais do I
Congresso Nacional de Engenharia de Petróleo, Gás Natural e Biocombustiveis 1 (2015).

[29] D. Brito Filho. Toxicologia humana e geral, Atheneu, Brasil (1988) 109-110.

[30] K-A. Kovar; M. Laudszun. Chemistry and reaction mechanisms of rapid tests for Drugs of abuse and precursors chemicals, Pharmazeutisches Institut der Universitat Tubingen - United Nations (1989) 8-9. 